Revista Española de Antropología Americana ISSN: 0556-6533

https://doi.org/10.5209/reaa.64969

\title{
Reconstruyendo rituales de la élite maya en las Tierras Bajas del norte: una mirada desde los códices mayas y Ek' Balam
}

\author{
Gabrielle Vail ${ }^{1}$
}

Recibido: 11 de noviembre de 2018 / Aceptado: 7 de marzo de 2019

Resumen. Los textos de los murales y las tapas de bóveda en Ek' Balam brindan una ventana única a algunos de los rituales practicados por el fundador dinástico y la población gobernante en el sitio, lo que permite una mayor comprensión de la cultura de élite del Clásico Tardío en las Tierras Bajas del norte durante este periodo de tiempo. La historia de Ek' Balam difiere de la de otras entidades políticas del Clásico del norte, con una fundación tardía de la dinastía real y vínculos aparentes con los sitios del periodo Clásico en las Tierras Bajas del sur y el oeste. Los almanaques de los códices mayas jeroglíficos, con antecedentes que datan de los períodos Clásico Tardío y Terminal, proporcionan una útil fuente de datos para interpretar referencias iconográficas y textuales de eventos rituales que ocurrieron a finales del siglo VIII y principios del IX en Ek' Balam.

Palabras clave: códices mayas; Ek’ Balam; rituales de la élite; ceremonias del portador del año.

\section{[en] Reconstructing Elite Maya Rituals in the Northern Lowlands: A View from the Maya Codices and Ek' Balam}

\begin{abstract}
Texts from murals and capstones at Ek' Balam provide a unique window onto some of the rituals practiced by the dynastic founder and the ruling population at the site, allowing a greater understanding of Late Classic elite Maya culture in the northern lowlands during this time period. Ek' Balam's history diverges from that of other northern Classic polities, with a late establishment of the royal dynasty and apparent ties to Classic period sites in the southern and western lowlands. Almanacs from the hieroglyphic Maya codices, with antecedents dating to the Late and Terminal Classic periods, provide a useful source of data for interpreting iconographic and textual references to ritual events occurring in the late 8th and early 9th centuries at Ek' Balam.
\end{abstract}

Keywords: Maya codices; Ek’ Balam; elite rituals; yearbearer ceremonies.

Sumario. 1. Yucatán durante el Clásico Tardío. 2. «Sacerdotes» y escribas del Posclásico. 3. Textos que hacen referencia a U Kit Kan Le'k. 4. Consideraciones finales. 5. Referencias.

Cómo citar: Vail, Gabrielle. 2019. «Reconstruyendo rituales de la élite maya en las Tierras Bajas del norte: una mirada desde los códices mayas y Ek'Balam». Revista Española de Antropología Americana 49 (número especial): 241-263.

En la búsqueda de una mejor comprensión sobre la cultura de la élite maya de Yucatán durante el Clásico Tardío y el Posclásico, la iconografía pintada y los textos jeroglíficos nos proporcionan una ventana excepcional hacia las prácticas rituales y los

1 Departamento de Antropología, Universidad de Carolina del Norte, Chapel Hill. vailg@email.unc.edu 
sistemas de creencias, tal como las comprendían los escribas y sus patrocinadores. En la siguiente discusión, recurriré a algunas de las fuentes más conocidas provenientes de Ek' Balam, centro del Clásico Tardío, y de los tres códices jeroglíficos mayas de la región de Yucatán, materiales sobre los cuales Alfonso Lacadena produjo un buen número de ideas clave durante su demasiado breve, pero maravillosamente productiva, carrera ${ }^{2}$.

\section{Yucatán durante el Clásico Tardío}

Ek' Balam es uno de los pocos sitios de las Tierras Bajas del norte que practicaron el señorío sagrado de manera similar a la forma asociada a las Tierras Bajas del sur, aunque su dinastía se fundó en una fecha mucho más tardía que la mayoría de las del área meridional. De acuerdo con el análisis de los textos jeroglíficos del sitio realizado por Lacadena (2004: 101), se piensa que el primer gobernante, Ukit Kan Le'k Tok', ascendió al trono en 9.16.19.6.1 (26 de mayo, 770 d.C.). Tomó el título de ajaw 'señor' en aproximadamente la mitad de los textos donde es mencionado y el de $k$ 'uhul ajaw ('sagrado señor') en dos de estas ocasiones, y también está asociado con el título de Kal[o']mte' ('supremo señor') cuatro veces. Además, era de descendencia real por su lado materno, ya que su madre es nombrada como la 'sagrada señora de Ho' (el estatus de su padre aún no ha sido establecido). Otros títulos tomados por U Kit Kan Le'k Tok' sugieren su asociación con un sitio conocido como Man y otro más que ha sido vinculado con Calakmul (Lacadena 2004: 99-100). Su referencia más frecuente es la forma corta de su nombre (U Kit Kan Le'k), misma que utilizaré en la discusión que sigue.

U Kit Kan Le'k es nombrado en 20 textos del sitio de Ek' Balam, registrado en siete tapas de bóveda, tres murales, cuatro objetos de su tumba y cuatro monumentos de piedra, varios de éstos dedicados por sus sucesores (Lacadena 2004). Su nombre está emparejado con el de varias deidades; por ejemplo, las tapas de bóveda sirven para asociarlo con Itzamná e Itzamná Mut (también conocido como la Deidad Ave Principal), el dios de los sustentos K'awiil y el dios del maíz. Estás deidades aparecen de manera destacada en los códices jeroglíficos mayas, a los que recurriremos para ayudarnos a comprender de mejor manera sus significados en estos contextos (ver discusión más abajo).

U Kit Kan Le'k es también nombrado en dos textos identificados como pertenecientes a otros sitios yucatecos y mencionado de manera retrospectiva por gobernantes más tardíos de Ek' Balam. Su reinado se extendió por lo menos 27 años y quizá tantos como 43, dependiendo de cuando ocurriera su muerte en relación al ascenso de su sucesor K'an B'ohb' Tok', en 9.13.3.10.14 (8 de enero, 814 d.C.) (Lacadena

\footnotetext{
2 Alfonso y yo iniciamos nuestros estudios de posgrado aproximadamente al mismo tiempo, y en nuestro trabajo los dos nos enfocamos en diversos aspectos del Códice de Madrid. Nos conocimos por vez primera en una conferencia organizada por Andrés Ciudad Ruíz (ver Lacadena 2000) que se llevó a cabo en Antigua, tras lo cual nos mantuvimos en frecuente comunicación. Fue un honor y un privilegio haber tenido a Alfonso como comentarista para el Simposio de Estudios Precolombinos que Christine Hernández y yo organizamos para Dumbarton Oaks en 2006, y el capítulo elaborado por él para el volumen Astronomers, Scribes, and Priests: Intellectual Interchange between the Northern Maya Lowlands and Highland Mexico in the Late Postclassic Period en el marco de este encuentro (Lacadena 2010) es, desde mi perspectiva, una de sus contribuciones más sobresalientes para los estudios mesoamericanos. Siempre recordaré su chispa y las numerosas y estimulantes conversaciones que sostuvimos cuando nos encontrábamos en conferencias en los Estados Unidos, Europa y Latinoamérica.
} 
2004: 101). Él fue el responsable de supervisar la mayor parte de las construcciones que se llevaron a efecto en la Acrópolis, además de estar asociado con varios tipos de rituales dinásticos, incluyendo aquellos que tenían lugar cuando un edificio era dedicado o sellado con una tapa de bóveda, un probable ritual del juego de pelota en el contexto de las ceremonias del Año Nuevo y aquellos que sucedieron al tiempo de su muerte. Los objetos con textos inscritos encontrados en su tumba incluyen un vaso para beber cacao, un ornamento en forma de pez y un perforador hecho de un fémur humano (Lacadena 2004: 75-83). Este último es descrito como perteneciente a un sacerdote nombrado Ukit Ahkan, personaje que posiblemente fue el padre de U Kit Kan Le'k (Lacadena 2004: 107-108). Su nombre corresponde al del Dios A' de los códices, quien tiene un importante papel en dos de los almanaques que son relevantes en la comprensión de los rituales que debieron haber sido oficiados por $\mathrm{U}$ Kit Kan Le'k y miembros de su corte real. Uno de estos representa un ritual de autosangrado, lo que concuerda con el perforador recuperado en la tumba.

Uno de los signos distintivos del reinado de U Kit Kan Le'k es su patrocinio de las artes escriturarias, especialmente las asociadas a los ah tzíb' o pintores. Es probable que en el sitio existiera un taller de escribanos, aunque aún falta por hallar la evidencia de éste (es posible que nunca se encuentre dado lo perecedero de los materiales utilizados por los pintores de los murales). Por fortuna contamos con evidencia de artistas que trabajaron en diferentes medios, provenientes de varios sitios contemporáneos a Ek' Balam, tales como Aguateca y Motul de San José, ambos ubicados en las Tierras Bajas del sur.

De especial importancia es la evidencia que procede de Aguateca. Tal y como sugiere la evidencia arqueológica, el sitio fue abandonado de manera súbita por su población (élite) en el 800 d.C., lo que implica que muchos de sus edificios fueron dejados en su estado de uso habitual. Varios de ellos, que estaban conectados al palacio real, pueden ser identificados como las residencias y talleres de los artesanos de la élite (Inomata 2011). Dos de ellos, la Casa de los Espejos y la Casa de los Escribas, contenían morteros y majadores utilizados para moler pigmentos, así como contenedores (mitades de conchas de caracol y almejas de río), que seguramente funcionaron como tinteros (Houston e Inomata 2009: 260-262). Un ornamento de concha con un texto jeroglífico y una representación al frente de un escribano, y un ornamento con la cara de un mono, que probablemente representa al patrono de los escribas, proporcionan evidencia adicional de actividades de escritura (Houston e Inomata 2009: 262-263). No se ha documentado testimonio de producción de códices (piedras machacadoras de corteza, etc.), aunque en las excavaciones realizadas en el sitio de Xultun, se han hallado estas piedras aplanadoras y otras pruebas que sugieren la producción de estos libros plegados. Sin duda estamos ante un hallazgo de importancia, si consideramos que el sitio rindió evidencia de 'micro textos' correspondientes al Clásico Tardío pintados en el muro de la estructura conocida como 'Los Sabios', que son similares a aquellos encontrados en los códices. Los estudiosos han sugerido que el muro sobre el cual fueron pintados estos textos pudo haber funcionado a manera de nuestros pizarrones modernos (Rossi et al. 2015).

Aunque no se ha encontrado ningún códice en Ek' Balam, es altamente probable que U Kit Kan Le'k haya empleado escribanos y guardianes de los días para escribir, interpretar, mantener y actualizar estos libros plegados. Sabemos, por fuentes más tardías, que Mayapán fue uno de los centros productores de códices durante el periodo Posclásico. Seguramente Ek' Balam constituyó un centro del saber en el noreste de Yu- 
catán durante los siglos VIII y IX. Si realmente fue similar a estos centros más tardíos, nos vemos en la posibilidad de reconstruir lo que habría ocurrido ahí a partir de las fuentes etnohistóricas como la Relación de las cosas de Yucatán de Diego de Landa.

«[Los sacerdotes] atendían al servicio de los templos y a enseñar sus ciencias y escribir libros de ellas.

Que enseñaban a los hijos de los otros sacerdotes y a los hijos segundos de los señores que les llevaban para esto desde niños, si veían que se inclinaban a este oficio.

Que las ciencias que enseñaban eran la cuenta de los años, meses y días, las fiestas y ceremonias, la administración de sus sacramentos, los días y tiempos fatales, sus maneras de adivinar, remedios para los males, las antigüedades, leer y escribir con sus letras y caracteres en los cuales escribían con figuras que representaban las escrituras» (Landa 2000 [c. 1566]: 38-39).

De hecho, sabemos por las fuentes etnohistóricas acerca de una ceremonia que se llevó a cabo en 1566 en la comunidad yucateca de Calotmul (aproximadamente a 20 km nor-noroeste de Ek' Balam) realizada por cuatro ah $k$ 'in, o sacerdotes, quienes se reunieron en la casa del Ah K'in May, o sumo sacerdote, para limpiar ritualmente varios códices mayas (Chuchiak 2004: 167). Esta reunión ceremonial, conocida como festival Pocam (que significa 'el lavado'), manifiesta varias similitudes a uno que tenía lugar en el mes de Wo del calendario yucateco descrito por Landa (2000: 121-122). Este era celebrado por «los sacerdotes, los médicos y hechiceros, que era todo uno» (Landa 2000: 121), quienes colocaban sus libros plegados sobre hojas frescas que habían sido preparadas por ellos mismos. Esto era acompañado por rezos a la deidad Itzamná en su aspecto de Kinich-ahau Itzamna [K'inich Ajaw Itzamná] 'Señor Ojo-solar Itzamná', la quema de incienso en braseros encendidos con el fuego nuevo, y la purificación de los libros con verdete ${ }^{3}$ mezclado con agua virgen (es decir, agua del bosque que no ha tenido contacto con una mujer). Después de la purificación, el Ah K'in May leía los pronósticos para el año de uno de los códices y exhortaba a los presentes a llevar a cabo los rituales necesarios (Landa 2000: 121-122).

Llama la atención de la descripción de Landa las delineaciones que habrían sido claras en la sociedad maya clásica y postclásica entre la clase intelectual, y que él agrupa como «sacerdotes, médicos y hechiceros». Seguramente entre estos se incluirían los escribas ( $a h t z$ ' $i b^{\prime}$ ) que pintaron e interpretaron los códices, quienes en ocasiones eran descritos como 'sabios' (itz 'at) y en otras como guardianes de los días (ah kin) (Reents-Budet 1994; Vail 2015). El hecho de que dichos personajes -incluyendo un sumo 'sacerdote'- estuviesen entre los participantes del ritual Pocam en las cercanías de Ek’ Balam a mitad del siglo XVI, sugiere que la tradición pictórica escribana observada en los muros y tapas de bóveda de las cámaras localizadas en el interior de la Acrópolis de Ek' Balam, continuó jugando un papel vital en la vida cultural del noreste de Yucatán durante los siguientes ocho siglos, a pesar de que la evidencia acerca de esta práctica sea escasa.

\footnotetext{
3 Verdete o cardenillo es una materia colorante verde claro hecha con el acetato o el carbonato de cobre, que se emplea en pintura y en tintorería (RAE), pero aunque Landa utiliza el término «verdete» en este contexto, en otros menciona un pigmento azul que los investigadores creen que sería el índigo mezclado con agua. Creo que fue este, en lugar de verdete, el que se usó para ungir los libros.
} 


\section{2. «Sacerdotes» y escribas del Posclásico}

Los sacerdotes referidos en la Relación de Landa como individuos que eran expertos en las artes, ciencias y cálculos calendáricos, fueron, sin lugar a duda, miembros de la élite (Vail 2015). Eran poseedores de una extensa base de conocimientos relacionada con el funcionamiento del calendario sagrado (260 días) y del calendario solar (365 días), así como de la interrelación entre ambos; y eran los responsables de programar las ceremonias que caían en «meses» específicos (periodos de veinte días, o winal) del año solar. Esta información fue registrada en códices como los tres que sobrevivieron provenientes de la península de Yucatán: Dresde, Madrid y París.

Las figuras que pueden corresponder al «sumo sacerdote» Ahkin May [Ah K'in May] de Landa (2000: 38) aparecen representadas un puñado de veces en los códices existentes, donde vemos a Itzamná, el creador masculino, y posiblemente la deidad del maíz, asumiendo este papel (Figura 1). El atuendo asociado con este rol sacerdotal incluye un tipo particular de tocado (referido en las fuentes coloniales como una 'mitra') y una capa o manto, igualmente un hisopo con la forma de una serpiente cascabel (Taube 1992: 34-35) ${ }^{4}$. En los tres ejemplos que muestran a Itzamná, esta deidad está asociada con tortugas (una aparece en el altar junto a él en la página 19b del Códice de Madrid; en las páginas 60c y 106a de este mismo manuscrito lleva en un cabo algo que se parece al caparazón de una tortuga). Como el abuelo creador, Itzamná es conocido como Xpiyacoc (coc hace referencia a un tipo de tortuga) entre los mayas k'iche' de los Altos de Guatemala (Christenson 2003: 62-63).

La asociación de Itzamná con la escritura y la pintura -es decir, su papel como escriba o patrocinador de esta actividad- se manifiesta claramente en varios de los almanaques del Códice de Madrid (páginas 22d-23d y 23c). De igual manera, la deidad de la lluvia Cháak representó este papel en varias ocasiones (en las páginas 22d-23d y 23c del Códice de Madrid, representado por K'uh, quien personifica el concepto de divinidad; y en la página $73 \mathrm{~b}$ del Madrid). La coloración azul aplicada a las deidades representadas que lo llevan a cabo sugiere que este acto es de naturaleza sagrada 5 .

El contexto de los almanaques en donde Itzamná o la deidad del maíz funcionan como sacerdotes puede ser relevante para la comprensión de cómo pudo haber sido representado o desempeñado este papel en las ciudades de las Tierras Bajas del norte del periodo Clásico maya, asumiendo que hubo continuidad en las ceremonias ejecutadas desde el Clásico Tardío hasta el Posclásico Tardío en esta región. El primero de los almanaques donde figura un sacerdote o sumo sacerdote, en la página $19 \mathrm{~b}$ del Códice de Madrid, representa un ritual colectivo que involucra el auto-sangrado de los genitales, mismo que es llevado a cabo por deidades ubicadas en las cuatro esquinas de la escena, así como por Itzamná al centro (Knowlton y Vail 2010; Vail y Hernández 2013: 390-391) (ver Figura 1). Landa (2000: 120) observa que, para la celebración de los rituales al inicio del año nuevo en Pop, la ceremonia era oficiada

\footnotetext{
4 El dios del maíz carece de los elementos de vestuario, pero mantiene el hisopo de serpiente en la página $111 \mathrm{~b}$ del Códice de Madrid, donde realiza un ritual asociado con el establecimiento de una colonia de abejas en su hogar.

5 El uso del azul en estos almanaques también recuerda al verdete mencionado en relación con la ceremonia $W_{o}$ (Landa 2000: 121). Además, la brea azul se encuentra de manera más generalizada durante las ceremonias celebradas en el mes Yaxk'in, cuando «[untaron] con el betún azul que hacían, todos los instrumentos de todos los oficios: desde el del sacerdote hasta los husos de las mujeres y los postes de las casas» (Landa 2000: 128). El color azul probablemente era usado para significar el acto de renovación (Vail 2005; Vail y Hernández 2013).
} 


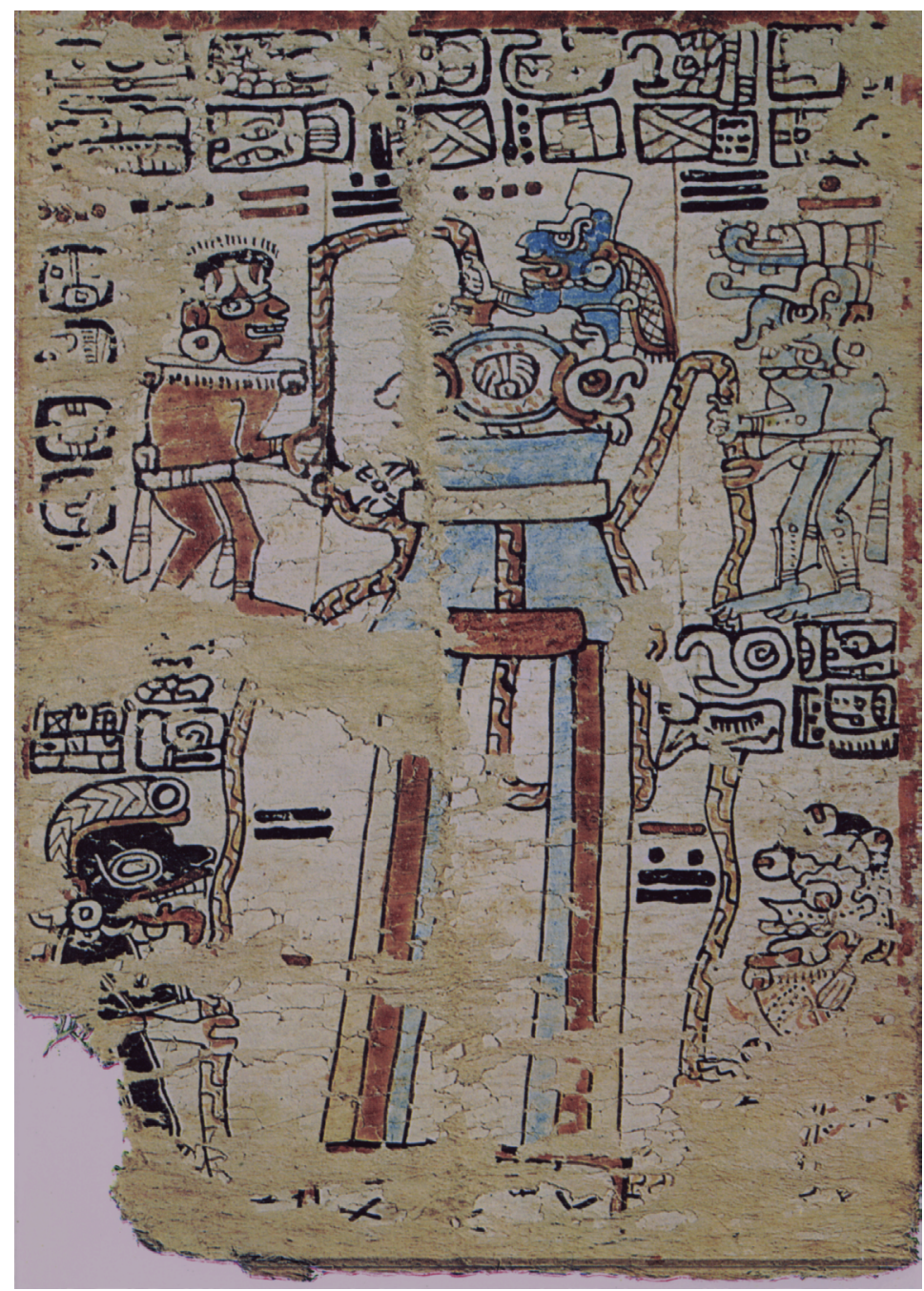

Figura 1. Códice de Madrid: almanaque en la página 19b (Codex Tro-Cortesianus, 1967). Reproducido con permiso, Museo de América, Madrid.

por un sacerdote «vestido de pontifical» (Landa 2000: 120), quien ocupaba el centro de la corte. Las deidades representadas en las cuatro esquinas de la página $19 \mathrm{~b}$ del almanaque Madrid, seguramente representan los «chaacs» que describe Landa (2000: 120) tomando sus posiciones en la plaza del templo, donde «tiraban un cordel nuevo de uno a otro lado, dentro del cual habían de entrar todos los que habían ayunado para echar al demonio»».

Aunque la ceremonia era abierta a todos los miembros de la comunidad, era de particular importancia para aquellos con estatus de élite -aquellos que Landa describe como «los señores, el sacerdote y la gente principal» (Landa 2000: 119)-, quienes ayunaban con antelación por periodos de semanas y hasta meses. La ceremonia concluía con el encendido del fuego nuevo por el sumo sacerdote, un acto que constituía una de sus más importantes funciones, y con la quema de incienso en braseros por 
parte de todos los participantes. Esta ceremonia también incluía el desecho ritual de los objetos utilizados durante el año anterior, mismos que eran renovados o remplazados a lo largo de los meses venideros.

Lo que Landa no describe en relación con la ceremonia Pop, pero que sí es mencionado en otra parte de la Relación, es el ritual de auto-sangrado de los genitales representado en el almanaque. La evidencia arqueológica sostiene que se trata de una actividad asociada con la cultura maya de élite del periodo Clásico, como también lo es la perforación de la lengua, un acto realizado por mujeres de élite en los murales del Cuarto 3 en Bonampak y por una diosa juvenil en la página 40c del Códice de Madrid (Vail y Stone 2002: 222).

Landa describe de la siguiente manera el ritual de auto-sangrado, que puede ser comparado con el representado en la página 19b del Madrid: «Otras veces hacían un sucio y penoso sacrificio, juntándose en el templo los que lo hacían y puestos en regla se hacían sendos agujeros en los miembros viriles, al soslayo, por el lado, y hechos pasaban toda la mayor cantidad de hilo que podían quedando así todos ensartados; también untaban con la sangre de todos aquellas partes al demonio...» (Landa 2000: 79). La «estatua del demonio» que aparece en el ejemplo del Códice de Madrid es Yax Kok, o 'primera tortuga'. Sobre su caparazón se observan gotitas de sangre.

Yax Kok (Ah Mut) [Yaxcoc-ahmut en el texto de Landa] es mencionado en relación a las ceremonias de Año Nuevo celebradas en los años que inician en el día Muluk del calendario sagrado. Landa anotó que para asegurar un buen año se elaboraba un «ídolo» de Yaxcoc-ahmut, mismo que era colocado en el templo (Landa 2000: 99). Se hacían ofrendas a la deidad incluyendo $k^{\prime} i k^{\prime}$, un incienso elaborado a partir de la resina del árbol de hule (que posiblemente es un sustituto de sangre humana, que también es conocido como $\left.k^{\prime} i k^{\prime}\right)$.

El sangrado y salpicado de sangre tiene conexiones a eventos creacionales y pudo haber funcionado como una acción asociada a ceremonias de renovación y ritos de recreación llevados a cabo de manera periódica por la cultura maya prehispánica y contemporánea, a menudo asociadas al comienzo del año nuevo (Taube 1988a; Vail y Looper 2015; Christenson 2016). Landa hace referencia a este ritual en su discusión de los cinco días «aciagos» (Wayeb') al final del año (p.e., Landa 2000: 99). Podemos observar altares en forma de tortuga con receptáculos para ofrendas (¿de sangre?), en contextos del Clásico Tardío (como Chichén Itzá) y en varios sitios que datan del Posclásico (Proskouriakoff 1962: 331-333; Taube 1988b: 193; Pugh et al. 2016; Harrison-Buck et al. 2018), parecidos a la escena contenida en la página 19b del Códice de Madrid. Más aún, este acto de auto-sangrado nos recuerda también a escenas provenientes de los códices de las Tierras Altas del México Central, que representan deidades sangrándose para originar nueva vida (Taube 1993: 44). En la página 19b del Códice Madrid, parecería que la sangre está alimentando al sol, toda vez que el signo que simboliza 'sol' $(k$ 'in $)$ aparece en la cuerda opuesta a la deidad pintada de rojo conocida como Akan (o Ahkan). Esto sugiere que en los tiempos en que el Códice Madrid fue pintado, existía en Yucatán una narrativa similar a la historia azteca en donde el sol requería de sangre para continuar su jornada, narrativa que pudo haber sido introducida por hablantes de náhuatl o que fue compartida de manera más amplia entre los dos grupos.

Otro elemento significativo del almanaque es su fecha de inicio, 4 Ajaw del tzolk'in. Creo que esto está funcionando a manera de instrumento mnemotécnico, señalando que los eventos representados se están llevando a cabo en tiempo primor- 


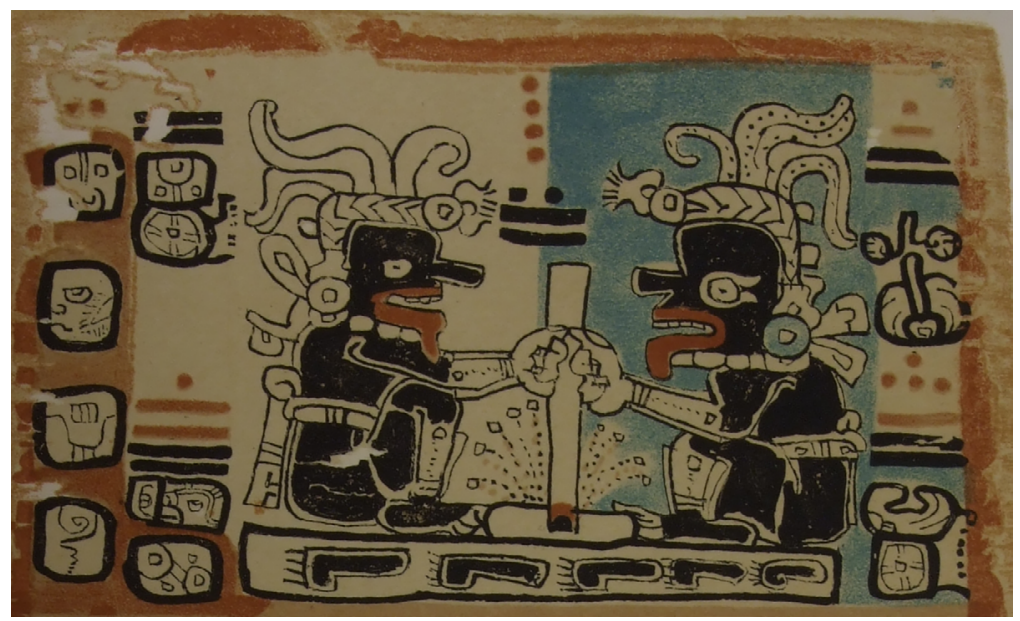

Figura 2. Códice de Madrid: almanaque en la página 51a

(Brasseur de Bourbourg 1869-70: Pl. 6).

dial, o, de otra manera, invocando este tiempo primordial, basado en la asociación del 4 Ajaw con la fecha era base 4 Ajaw 8 Kumk'u asociada a los eventos míticos fundacionales de 3114 a.C. (Vail y Hernández 2013: 385-386, 390). Si este es el caso, es notable que otro almanaque que empieza en 4 Ajaw (el que aparece en la página 51a del Códice de Madrid; Figura 2) representa versiones emparejadas (o gemelas) de la deidad de los mercaderes, quien aparece iniciando fuego nuevo, otro evento que Landa asocia a las ceremonias de Año Nuevo enfatizando la renovación (Vail 2005). Al respecto, se debe notar que la deidad de los mercaderes es una de las deidades que aparece participando en el ritual de auto-sangrado en la página $19 \mathrm{~b}$ del Madrid, por lo que esto sugiere aún más el vínculo existente entre las actividades representadas en ambos almanaques (Vail y Hernández 2013: 395). El tejido de tela está también asociado a la fecha 4 Ajaw (en las páginas 102c y $102 \mathrm{~d}$ del Códice Madrid). A este respecto, es de interés que la tela es una de las ofrendas dadas a Yaxncoc-ahmut en relación con las ceremonias de los portadores del año Muluk, de acuerdo con lo relatado por Landa (2000: 99).

Pruebas de contextos arqueológicos y epigráficos, así como el hecho de que una parte significativa del contenido de los códices mayas del Postclásico puede ser atribuida a originales del periodo Clásico (ver, por ejemplo, Lacadena 2004; Bricker y Bricker 2011; Saturno et al. 2017), proporcionan un fuerte apoyo a la hora de teorizar que los sacerdotes y la población de élite gobernante en Ek' Balam y otras capitales de las entidades políticas mayas del Clásico Tardío participaron en rituales similares a los descritos. Por lo que respecta a la escena representada en la página 19b del Madrid, los estudiosos han sugerido previamente que esta puede estar relacionada de manera específica a la pintura y colocación de tapas de bóveda en sitios del Clásico Tardío, tales como las documentadas en Ek' Balam (Figura 3). Este argumento surge a partir del hecho de que en Ek' Balam los textos de las tapas incluyen el verbo makaj, cuyo significado es 'fue cubierto'. A esto le sigue en algunos ejemplos una referencia a $u$ wayil $u k^{\prime}$ 'aal y el nombre del ajaw, que Lacadena (2004: 38) leyó como «El lugar de dormir del ajaw, su recinto», todo esto haciendo 


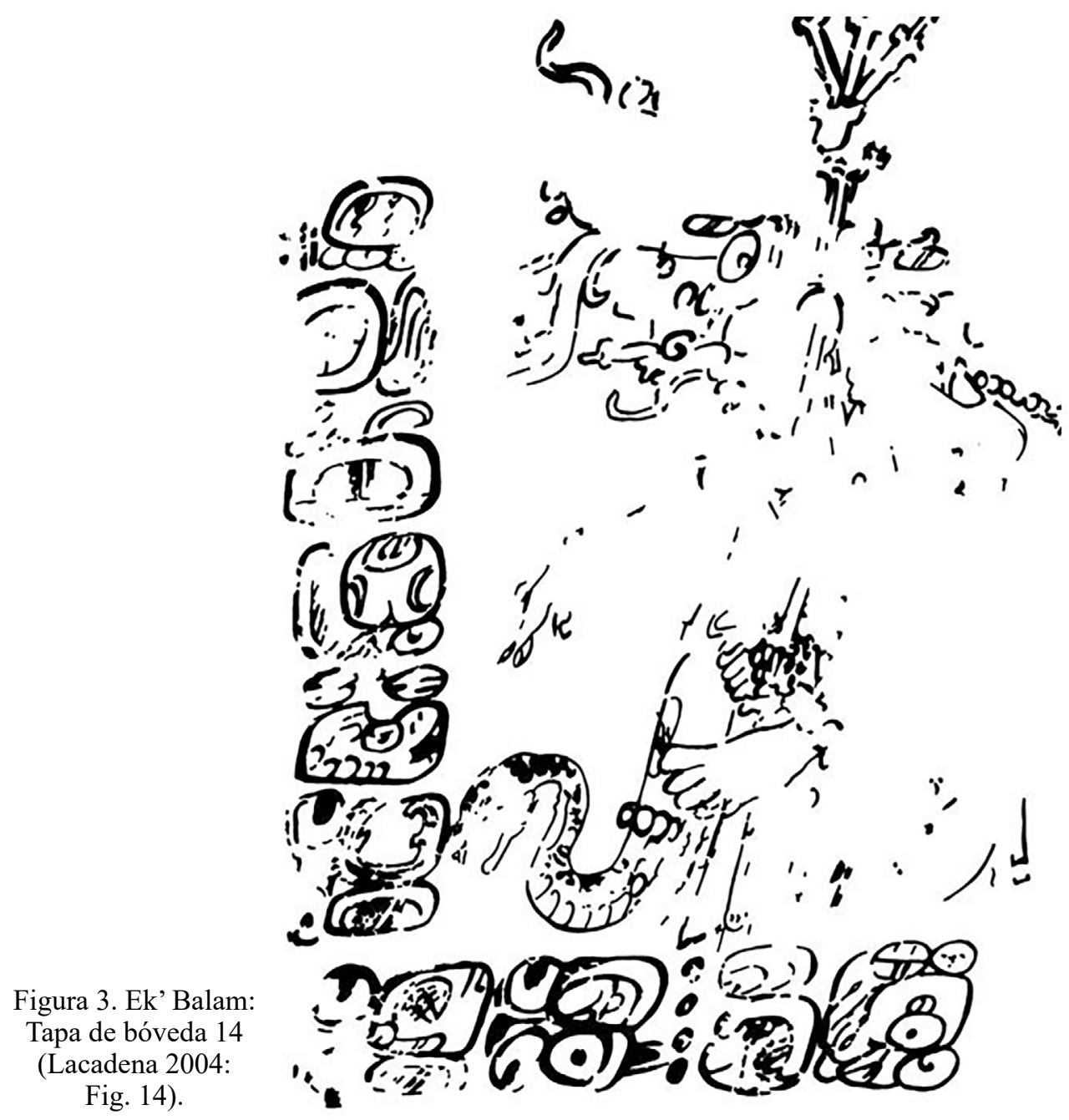

referencia al cierre de este espacio. Kerry Hull y David Carrasco (2004) notaron que la página 19b del Madrid podría mostrar un evento mak similar, con base en la lectura de tortuga como mak en lugar de kok (mak puede significar tanto 'tortuga' como 'cubrir' en maya yucateco; Barrera Vázquez et al. 1995: 480). De acuerdo con su interpretación, la tortuga que aparece en la cúspide del templo en la página $19 \mathrm{~b}$ del Madrid tiene el mismo papel que el verbo mak en los textos de las tapas de bóveda de Ek'Balam. Ambos hacen referencia al cierre o sellado ritual de una cámara en una estructura, como parte de un ritual fundacional o dedicatorio. La referencia en este almanaque indica que esta estuvo acompañada de una ceremonia de purificación, así como del ritual de auto-sangrado, para santificar el espacio. Si en estos rituales hubo o no invocaciones del tiempo primordial en lugares como Ek' Balam, sigue siendo una pregunta que requerirá de más análisis. Sin embargo, las fechas asociadas con los textos de las tapas de bóveda en Ek' Balam no parecen haber tenido esta función. 


\section{Textos que hacen referencia a U Kit Kan Le'k}

\subsection{Las Tapas de U Kit Kan Le'k}

Cada una de las siete tapas de bóveda dedicadas a U Kit Kan Le'k (Tok') representan a un ser sobrenatural o al gobernante en la apariencia de un ser sobrenatural (ver Lacadena 2004: Figs. 8, 10, 11, 14-17). Dos de ellas (Tapas 6 y 14) presentan a K'awiil (ver Figura 3), el dios del relámpago y los sustentos, sentado en un cojín de regencia cubierto por una piel de jaguar (Lacadena 2004: 33, 40) (ver Figura 2). Esta deidad aparece comúnmente en los monumentos labrados de las Tierras Bajas del sur, donde era invocado por los miembros de la familia reinante, quienes reclaman sus poderes de invocar al relámpago y la munificencia de la tierra. Asociaciones similares son sugeridas por el tocado de K'awiil que aparece en el almanaque de $k^{\prime}$ 'atun del Códice de París (Figura 4), que está siendo ofrecido por una serie de trece deidades (correspondientes a los trece $k^{\prime}$ 'atunes en un ciclo de 256 años), a una figura sentada en un trono formado por el cuerpo de un ser cocodriliano atado encima de una banda celeste (nótese también que las patas del trono están formadas por un segundo ser cocodriliano). Esta iconografía alude al ascenso al cargo, como lo sugieren las Estelas 6 y 11 de Piedras Negras y la Estela 32 de Naranjo (Love 1994: 17, 26). La asociación de K'awiil con la agricultura y la abundancia de la tierra es resaltada en varias tapas de bóveda del área maya del norte que datan de un periodo de tiempo similar al de Ek' Balam (Knowlton 2010: 62-63).

Otras dos tapas de Ek' Balam (Tapas 7 y 19) representan la forma aviar de Itzamná (Lacadena 2004: Figs. 11, 17), conocida como la Deidad Ave Principal, y una tercera tapa (Tapa 3) muestra a Itzamná en su carácter antropomorfo. En su rol de creador masculino primordial, Itzamná actúa como vaticinador y fuente del conocimiento esotérico (Taube 1992: 36), papel que ya fue remarcado en la discusión previa de los códices mayas. Ya desde el periodo Preclásico (400 a.C.-250 d.C.), Itzamná toma a veces rasgos aviares, particularmente en escenas que involucran los árboles direccionales del mundo. De acuerdo con Karl Taube y colaboradores (Taube et al. 2010), estos ejemplos tienen claras asociaciones con el maíz y la fertilidad agrícola. La forma aviar de Itzamná aparece también en varias páginas del almanaque k'atun del Códice de París (ver Figura 4), donde funciona como el muut, o pronóstico, para ese periodo de tiempo. Esta asociación surge del hecho de que, para las culturas mayas yucatecas, la palabra muut puede significar 'ave' o 'augurio' (Barrera Vázquez et al. 1995: 542).

De las tapas que contienen fechas, la más temprana (Tapa 7) fue dedicada en el año 775 d.C. y la más tardía (Tapa 19), en 797 o 802. Ambas muestran a Itzamná en su forma aviar. La Tapa 15 no contiene fecha, pero se cree que está asociada con el entierro de U Kit Kan Le'k, lo que sugiere que es la más tardía de la serie, fechándose después del 806 d.C. (Lacadena 2004: 43). Representa a U Kit Kan Le'k Tok' como el dios del maíz (Lacadena 2004: Fig. 15), la encarnación del ciclo de nacimiento, muerte y renacimiento de la cosecha de maíz (Lacadena 2004). Esto recuerda a representaciones similares de Pakal en Palenque, fechadas durante su reinado en el siglo VII (Stuart y Stuart 2008; Filloy 2018).

Si bien la lectura del texto jeroglífico como «El cuarto, el recinto de Ukit Kan Le'k» tiene mucho sentido, se podrían sugerir otras interpretaciones posibles basadas en la lectura de way [wáay] como 'espíritu' (Bricker et al. 1998: 301) o como 


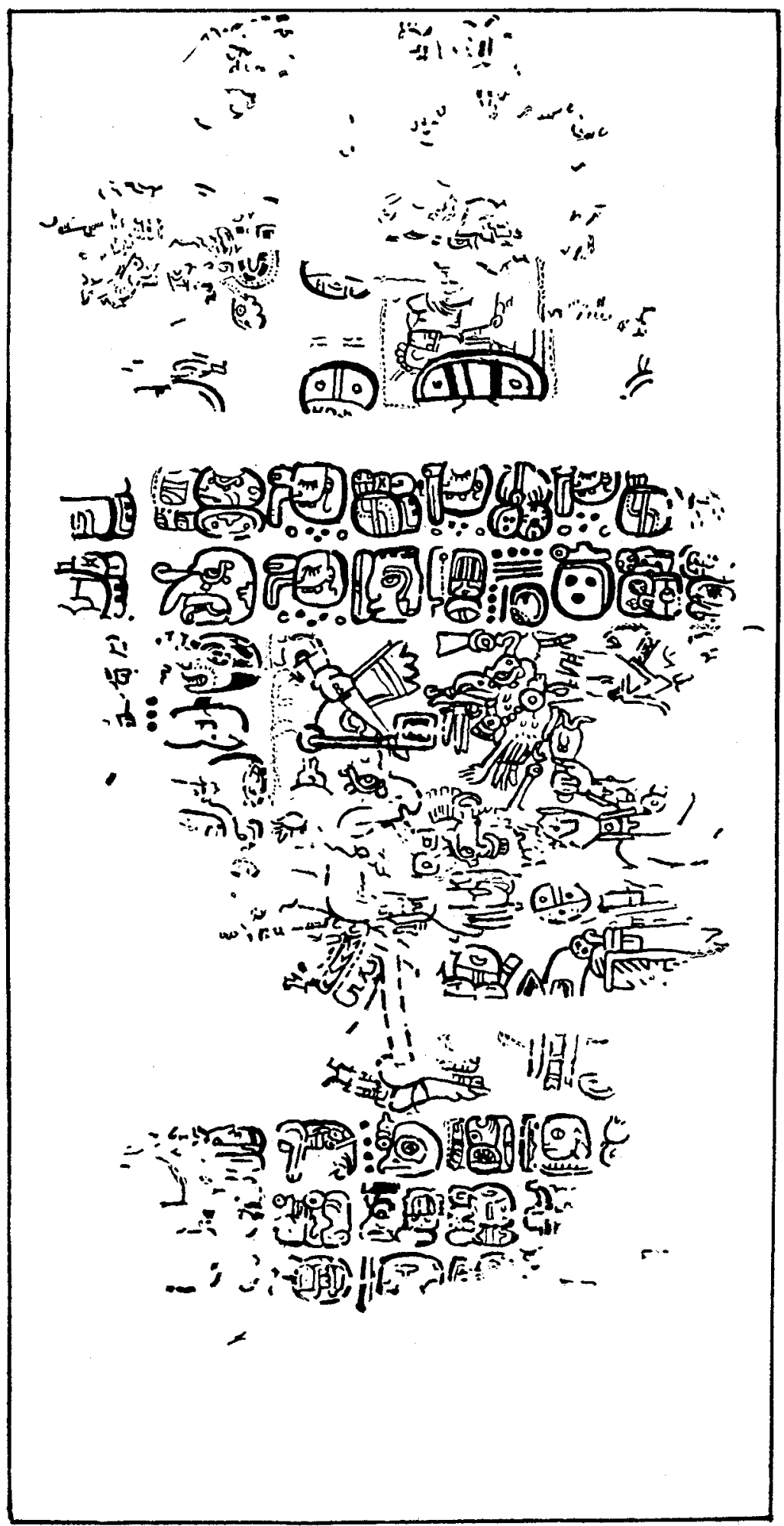

Figura 4. Códice de París: página 11 (Villacorta y Villacorta 1976: 200). 
'[animal] alter ego' (Martínez 1929: 888-889). Si aplicamos esta lectura al texto makaj $u$ wayil de la tapa de bóveda, este podría ser interpretado como «Su espíritu acompañante fue cubierto». Por otra parte, además de su interpretación como 'recinto', $k$ 'al también significa 'cerrar, cubrir, o encerrar' (Barrera Vásquez et al. 1995: 368). Si se interpreta de este modo, el texto resultante pudo haber representado dos frases distintas: makaj u wayil «Su espíritu/alter ego es cubierto» y u k'aal ukit kan $l e$ ' $k$ «es el cubrimiento de U Kit Kan Le'k». Esta interpretación de way encaja particularmente bien con la evidencia de las tapas si consideramos por ejemplo a K'awiil con su pierna de serpiente y el aspecto aviar de Itzamná. Sin embargo, si decidiéramos interpretarlo de este modo, la pregunta sería: ¿Qué significa 'cubrimiento' cuando es utilizado en referencia a figuras humanas, deidades, o animales?

Un ejemplo bien conocido de esta expresión lo tenemos en la Estela 1 de Piedras Negras en donde el verbo makaj aparece en referencia a la Señora Naman a tan solo cinco días de lo que se cree sería su matrimonio (nawaj) con el Gobernante 3. La frase en cuestión ha sido interpretada para referirse a una ceremonia de compromiso (Houston y Stuart 2001: 67), un rito de pubertad (Mathews 1993: 105) o un acto de aislar (Clancy 2009: 75). No está claro lo que este contexto y las tapas de Ek' Balam tengan en común, a menos que Ukit Kan Le'k Tok' hubiese sido igualmente aislado o realizara algún tipo de ritual de ayuno previo a la ceremonia dedicatoria enfatizada en las tapas. Podría ser el caso que su 'cubrimiento' se refiera a su conversión en (es decir, asumiendo la persona de) la deidad o espíritu acompañante representada en la tapa. Esto sugeriría un paralelismo con la página 19b del Madrid, pudiéndose asumir que U Kit Kan Le'k estaría tomando el papel de Itzamná y los otros participantes (que no están nombrados en la tapa) tomarían los atributos de (o se convertirían en) otras deidades durante la duración de la ceremonia.

\subsection{Murales de Ek' Balam}

\subsubsection{Mural A}

E1 Mural A, o Mural de los 96 Glifos (Lacadena 2004: Figs. 18a-e), fue pintado en la pared interior norte del Cuarto 29-sub, localizado en la Acrópolis. Registra dos fechas -9.16.19.3.12 11 Eb' 10 Sotz' (7 de abril, 770 d.C.) y 9.16.19.6.1 8 Imix 19 Xul (6 de mayo, 770 d.C.)- y es el texto con fechas más temprano de Ek' Balam. Parece ser la fecha de ascenso de U Kit Kan Le'k Tok', aunque inicia con una declaración anunciando el arribo de otro personaje, Chak Juntuuw Chan Ek, quien es descrito como el k'uhul ajaw, el kalomte' del norte y un b'akab' (Lacadena 2004: 111-112). Esta llegada ocurrió en la fecha tzolk'in 11 Eb', y Lacadena nota su semejanza con la llegada de Siyaj K'ahk' a Tikal en un periodo mucho más temprano. Esta referencia aparentemente deliberada a un evento pasado altamente cargado de contenido y la similitud de la estructura y el formato del texto con el Tablero de los 96 Glifos de Palenque (que data del año 764 d.C. durante el reinado de Pakal), sentaron las bases para la fundación del linaje dinástico en Ek' Balam.

Si bien la caligrafía y el estilo del texto son un homenaje a una tradición «clásica» occidental y meridional, contiene varios rasgos que ayudan a definir una identidad yucateca emergente para el sitio -por ejemplo, las series de 48 fechas del tzolk'in que funcionan como números de distancia entre 11 Eb' 10 Sotz' y 8 Imix 19 Xul (Lacadena 2004: 112)-. En las páginas 12b-18b del Madrid (Figura 5) aparece un 


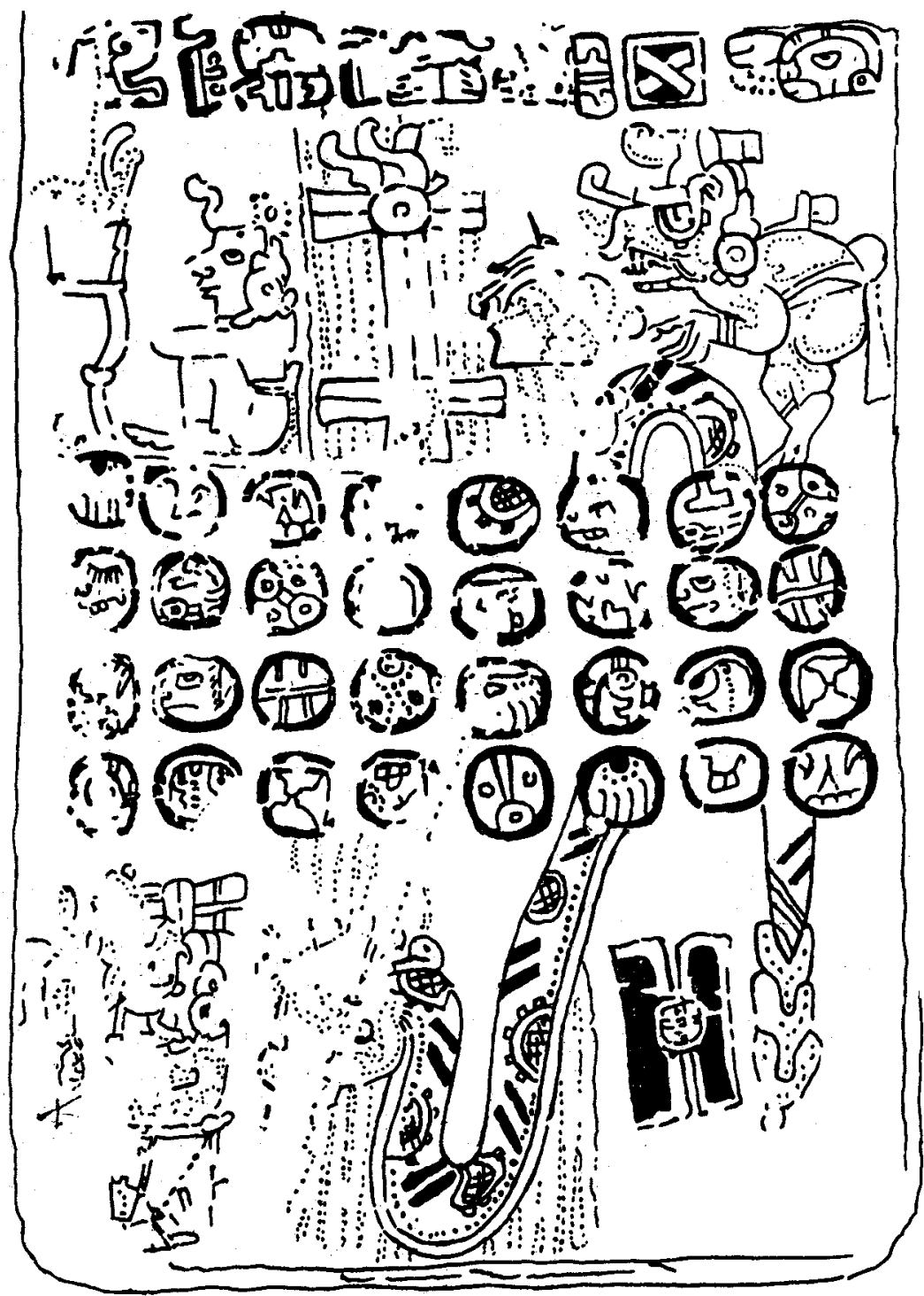

Figura 5. Códice de Madrid: página 13b, parte de un almanaque que se extiende desde la página $12 \mathrm{~b}$ a $18 \mathrm{~b}$ del códice (Villacorta y Villacorta 1976: 250).

formato similar de un texto escrito horizontalmente que registra fechas sucesivas en el tzolk'in. Las serpientes que se entrelazan entre las fechas de estas páginas recuerdan los «números de serpientes» en el Códice de Dresde (ver, por ejemplo, pp. 61-62 y 69 del Dresde; Figura 6), un rasgo que también se encuentra en una vasija de estuco pintado de Ek' Balam (Lacadena, comunicación personal a los Brickers, 14 de noviembre de 2008; citada en Bricker y Bricker 2011: 508).

Otro punto en común entre las páginas mencionadas en el Códice Dresde y los textos del Mural A es el uso del verbo pat, que significa 'formar, dar forma, mol- 


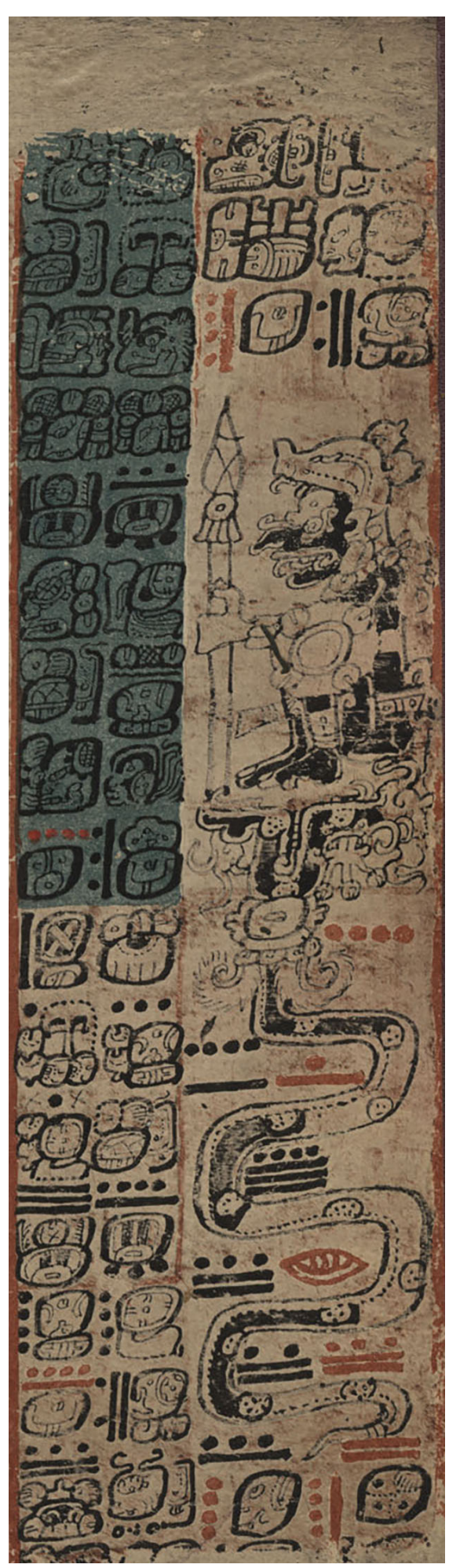

dear' (Barrera Vásquez et al. 1995: 632). En el Códice de Dresde aparece después de una referencia a los 'tres dioses nacidos juntos' y se refiere a la creación del periodo de tiempo conocido entre arqueólogos como el b'ak'tun (y entre los mayas como el pih), periodo de aproximadamente 400 años. Los textos en las páginas 61 y 69 del Dresde se centran en eventos ocurridos durante tiempos primordiales, que incluyen los «cinco arribos [¿de Venus?] desde el agua», que es una referencia a la creencia mesoamericana de que la estrella Matutina y la Vespertina surgieron de una cueva en el mar previamente a ascender al cielo. Esto parece estar representado en la página 69 del Dresde en términos de una imagen de un Cháak pintado de negro con los atavíos de un guerrero emergiendo de las fauces abiertas de una serpiente (Vail y Hernández 2013: 158-159) (ver Figura 6). En Ek' Balam, el verbo pat es utilizado en la expresión $i$ patlaj talol ajaw «entonces se convirtió en el rey de Talol,» que se refiere al acenso al poder a U Kit Kan Le'k (Lacadena 2004: 114). Esto ocurrió en 770 d.C., cercano en el tiempo en que fueron escritas versiones más tempranas de los textos astronómicos del Dresde (las fechas asociadas incluyen 759 d.C., 779 y 786 d.C.) (Bricker y Bricker 2011).

Dado el nivel de comunicación que se ha documentado que ocurrió con los responsables de las versiones posclásicas de los códices existentes, parece muy probable que los letrados de Ek' Balam conocieran una narrativa similar a la registrada en el Códice de Dresde. Si bien solo podemos especular acerca de si los rituales que representan el surgimiento de Venus similares a aquellos que suceden en la página 69 del Dresde tuvieron lugar en Ek' Balam, esto parece muy probable dado que la entrada principal a la Acrópolis tenía la forma de una boca de witz

Figura 6. Códice de Dresde: página 69 (Förstemann 1880). 
o la entrada simbólica de una cueva. Dicho de otra manera, durante las fechas apropiadas -como se definen en tablas como aquellas utilizadas para predecir las fechas de la aparición y desaparición de Venus en las páginas del Dresde 46-50- podemos especular que el gobernante o sacerdote aparecía emergiendo del inframundo (el interior de la Acrópolis) ataviado a la manera de Cháak en el aspecto de Venus de Estrella Vespertina, llevando un tocado de pecarí, el cuerpo pintado de negro y sosteniendo una lanza y escudo.

En otras épocas del año, pudo tener lugar un surgimiento simbólico similar en relación al nacimiento de las lluvias o de la temporada de lluvias. Esto está representado en las páginas 31b-35b del almanaque Dresde donde Cháak, con su hacha de rayo levantada, emerge de las fauces abiertas de una serpiente cuyo cuerpo enroscado rodea una poza de agua. Lo anterior parece representar su surgimiento de la «tierracueva,» que es una descripción acertada de lugares que se asemejan a la entrada de la Acrópolis de Ek' Balam. En este lugar, Cháak se asocia con el encendido de fuego nuevo y nueve ofrendas de $k$ ' $i k$ ' (incienso de sangre o hule) (Vail y Hernández 2013: 124-129).

\subsubsection{Mural B}

E1 Mural B (Lacadena 2004: Fig. 19) fue pintado 36 años después del Mural A. Aparece en la misma pared, por debajo y a la izquierda del Mural A. Lacadena (2004: 55) leyó la fecha inicial como 1 Ajaw 3 Wayeb (el mes está escrito como u-WAYHAB', Uwayaab '), correspondiente a 9.18.15.9.0 (16 de enero, 806 d.C.) y nota que a continuación le sigue un logógrafo representando una cancha de juego de pelota, lo que sugiere que pudo haberse llevado a cabo un juego de pelota para celebrar los rituales de Wayeb '6. Parece que también hay una referencia a la deidad B'olon Tz'ak Ajaw o B'olon Tz'ak[ab'] Ajaw, conocido a través de los textos del periodo colonial (Lacadena 2004: 55). Uno de los contextos en el que esta deidad juega un papel clave es en los festivales Wayeb' descritos en la Relación de Landa, particularmente aquellos asociados con el sur y con los años $K^{\prime}$ an (Landa 2000: 96-98). En el Códice de Dresde, esto correspondería a los años Lamat.

Aunque estas ceremonias eran de naturaleza comunitaria, las figuras principales eran el sacerdote que dirigía la acción ritual y el principal, cuya casa formaba el centro de este evento. Uno de los primeros asuntos que se abordaban era el de hacer una «estatua» de la deidad Bolon-tz'acab [B'olon Tz'akab' en la ortografía actual], «la que ponía en casa del príncipe, aderezada en lugar público y al que todos pudiesen llegar» (Landa 2000: 96). Después de una procesión a la entrada del pueblo con otra imagen de la deidad (esta de barro), a la que se le sacrificaba un pavo y se ofrecía incienso, la procesión regresaba a la casa del principal, donde se colocaba la imagen de la deidad frente a la estatua de Bolon-tz'acab y se hacían varias ofrendas de comida y bebida. En el transcurso de los siguientes cinco días del periodo $\mathrm{Wa}$ yeb', se hacían ofrendas de incienso a la imagen y estatua, pero al final del Wayeb' la estatua de Bolon-tz'acab era llevada al templo y la imagen era puesta en el acceso este del pueblo, donde permanecería hasta los rituales Wayeb' del siguiente año (Landa 2000: 96-98).

\footnotetext{
${ }^{6}$ Lo que parece ser un ritual del año nuevo se hace referencia en las pinturas murales de los sabios en Xultun (ver Saturno et al. 2017).
} 
El pasaje del Mural B que hace referencia a un juego de pelota que se llevó a cabo durante el Wayeb', hace recordar la discusión de Allen Christenson sobre una ceremonia descrita por Las Casas (1967 [1550], II.clxxvii.149) y Ximénez (1929-31 [1722], I: 81-101), que tuvo lugar en los Altos de Guatemala «en donde sus reyes re-escenificaban la muerte simbólica y descenso de sus dioses hacía el inframundo, simbolizado por una cancha de juego de pelota hundida, donde enfrentaban a los señores de la muerte» (traducido de Christenson 2001: 189). Durante estos días «cerrados», mientras los reyes estaban envueltos en esta batalla simbólica, se sacaban imágenes ricamente ataviadas de dioses del inframundo para que, de manera temporal, tomaran el lugar de los legítimos gobernantes. Al igual que las imágenes que describe Landa, estas eran cargadas en procesión y se les daban ofrendas, a fin de asegurar que no traerían enfermedades o muerte a la comunidad. Una vez que los reyes regresaban exitosamente tras vencer a los dioses de la muerte, se guardaban las imágenes hasta el año entrante, o bien se destruían.

Es probable que rituales como este se hayan llevado a cabo en Ek' Balam, como lo sugiere las alusiones a la cancha del juego de pelota y el periodo Wayeb' del texto del Mural B. En las páginas 25-28 del Códice de Dresde (Taube 1988a; Vail y Looper 2015) se muestran unas versiones abreviadas de las ceremonias de Wayeb' que describe Landa (Figuras 7-8), aunque reflejan un sistema de portadores de años más temprano, similar al que se habría utilizado en Ek' Balam. Ahí, la fecha 0 Pop estaría asociada con los días $I k^{\prime}, M a n i k$ ', $E b^{\prime}$ y Kab'an y 1 Pop (el comienzo del nuevo año) con $A k^{\prime} b$ 'al, Lamat, B'en y Etz'nab'.

No se nombra de manera específica en estas páginas a la deidad B'olon Tz'akab', pero los epigrafistas creen que la figura conocida como Dios K, o K'awiil, que aparece sentado en un templo en la página 25 b del Dresde (Figura $7 \mathrm{a}$ ), es una variante de esta deidad. Esta sugerencia se basa en la asociación de esta figura con las ceremonias Wayeb' que tienen lugar en el sur (Seler 1902-23, I: 377; Taube 1988a: 73). Las ofrendas hechas a K'awiil incluyen incienso de pom, que puede verse quemándose en un incensario, tamales o tortillas con iguana y tortillas de maíz o alimentos en general.

K'awiil también aparece como la deidad realizando las ceremonias que marcan el inicio del nuevo año en la parte baja la página 26 del Dresde (Figura 7b), que incluye «plantar» un árbol simbolizando el tiempo de la creación, sacrificando un pavo, derramando incienso y haciendo varios tipos de ofrendas de alimentos ${ }^{7}$. Los pronósticos asociados a esta escena apuntan hacia un año de abundancia, un año repleto de sustentos de maíz (Vail y Hernández 2002-2018). Podría ser de importancia el hecho de que el Mural B se centra en esta ceremonia del portador del año (corresponde a los días Lamat) en particular, dada la representación de U Kit Kan Le'k como K'awiil en varias tapas de bóveda, así como su toma del nombre de la deidad Chan ('Cielo') $\mathrm{K}$ 'awiil en el texto de un mural localizado en otro cuarto de la Acrópolis.

El descenso simbólico al inframundo asociado con el juego de pelota puede estar representado en las dos últimas páginas de este almanaque (páginas 27 y 28 del Dresde; Figura 8), resaltando las ceremonias del Wayeb’. Aquí podemos ver las figuras identificadas como los Mam (abuelos y/o ejecutantes ceremoniales) localizados

\footnotetext{
Hay evidencias fundadas que sugieren que esta imagen debería aparecer en lugar de la página 28c del Dresde, y viceversa (Thompson 1934: 214; Taube 1988a: 221-222). Si este fuera el caso, entonces K'awiil estaría asociado con años Lamat.
} 


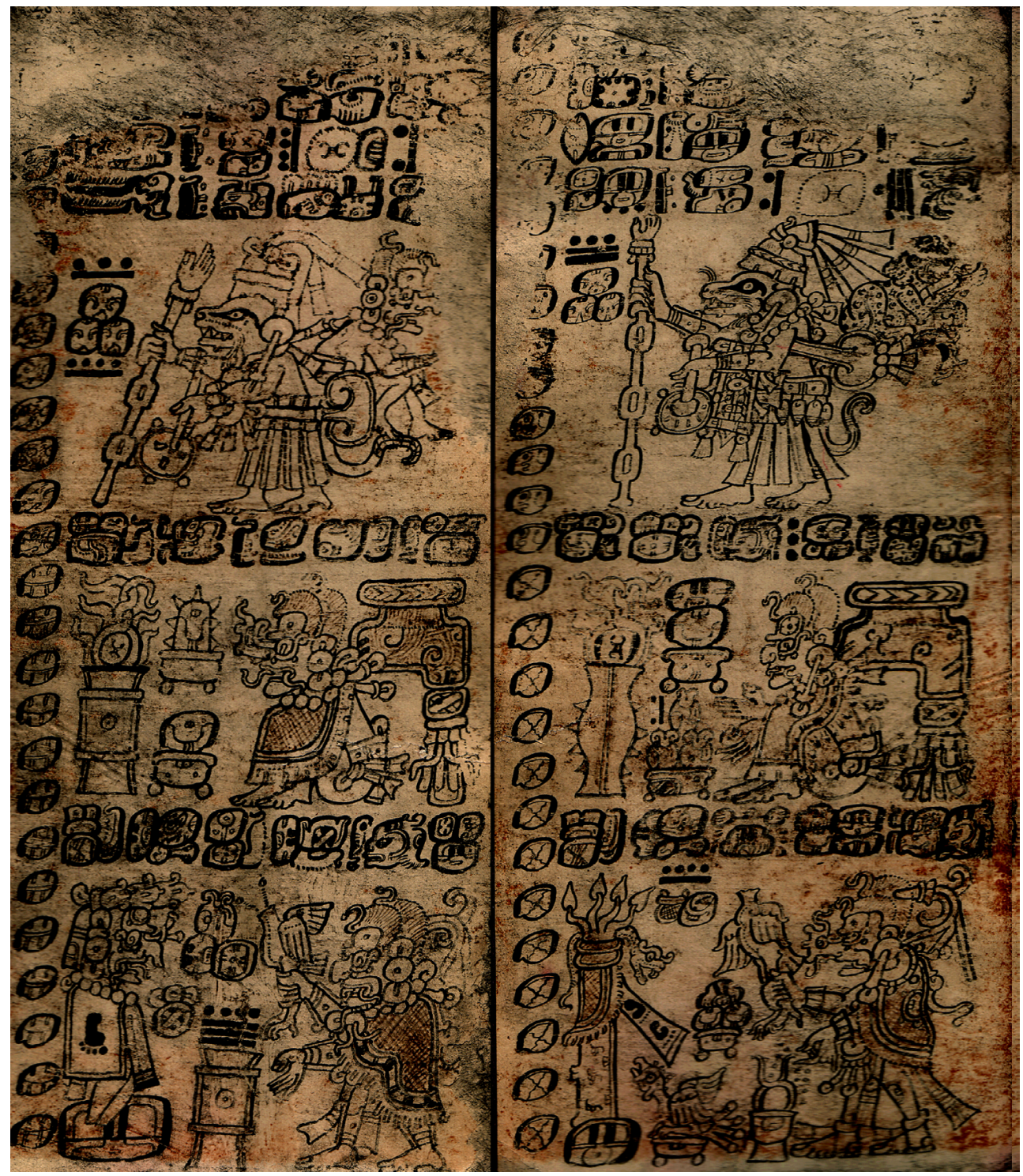

Figura 7. Códice de Dresde: páginas 25-26 (Förstemann 1880).

en el interior de cenotes -otra entrada simbólica al inframundo-. Los Mam están cargando sobre sus espaldas deidades que simbolizan al año viejo (el dios del maíz y el dios de la muerte). Estas escenas pueden estar representando su resurgimiento tras la batalla simbólica, toda vez que los textos jeroglíficos incluyen el verbo tal-iy 'llegaron [de]', seguido de una referencia al norte en la página 27 del Dresde y al oeste en la página 28 del mismo (Vail y Hernández 2002-2018). El sur y el este no están asociados a la misma iconografía, lo que quizá sugiera que la competición simbolizada por el descenso del juego de pelota al inframundo era solo necesaria durante los años asociados con el norte y oeste. 


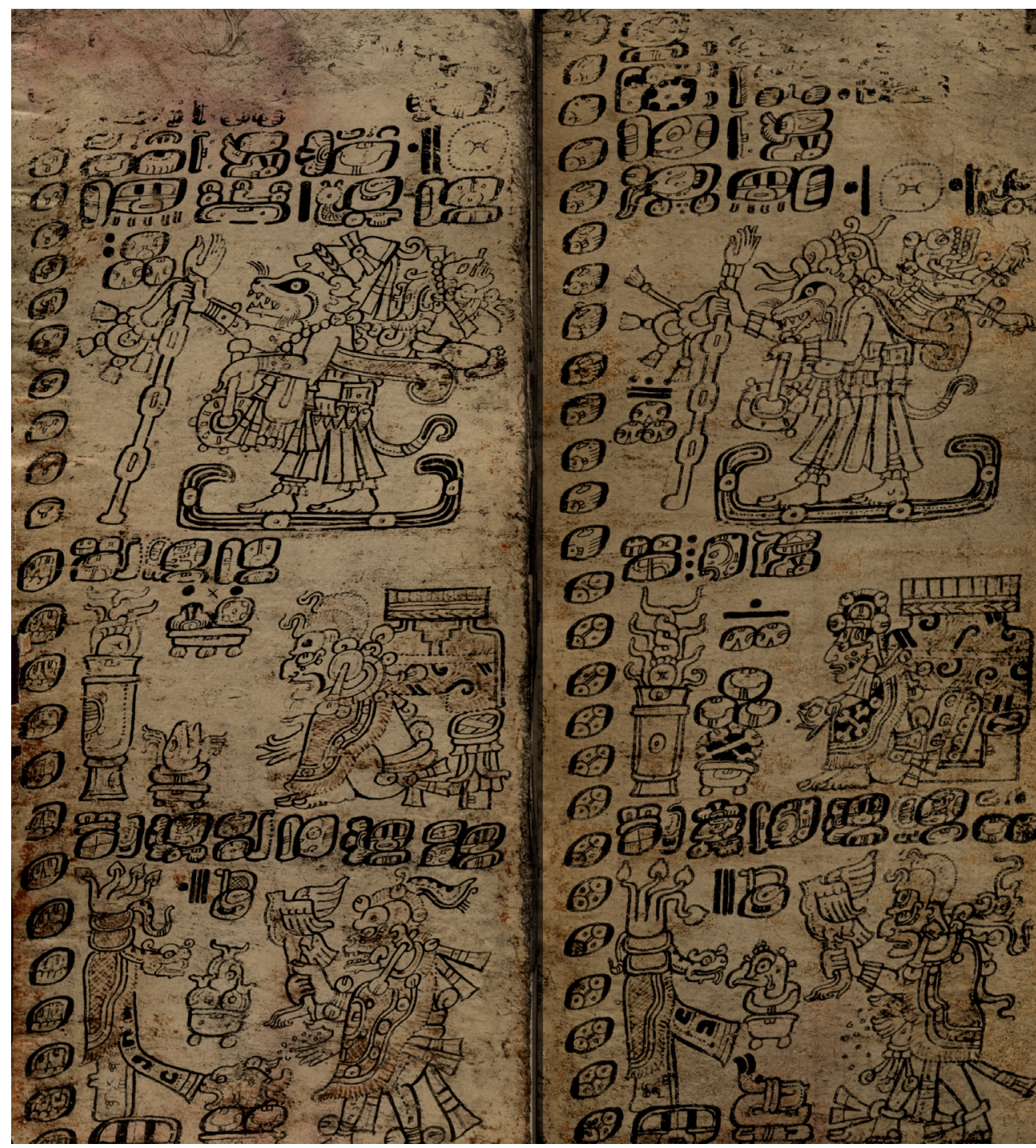

Figura 8. Códice de Dresde: páginas 27-28 (Förstemann 1880).

\subsubsection{Mural del Cuarto 22}

Otro mural con vínculos a los rituales de los portadores del año es el que se encuentra en la pared norte del Cuarto 22 en la Acrópolis (Figura 9), que puede ser fechado para los años 783 d.C. y 784 d.C. En este, U Kit Kan Le'k es de nueva cuenta el protagonista, aquí además con el título de Chan K'awiil, o 'Cielo K'awiil'. La reconstrucción de Lacadena apunta al hecho de que las fechas registradas remarcan un final de tun (14 tuun k'a'y[i]), que él traduce a «el anuncio del $14^{\circ}$ tun». Esto es seguido por la fecha de rueda calendárica 3 Lamat 1 Wayeb', que puede reconstruirse como 9.17.13.3.8 (20 de enero, 784 d.C.) (Lacadena 2004: 86-87). El mural termina con 
una serie de fechas de la Rueda Calendárica, que Lacadena (2004: 87) reconstruye como sigue (las fechas de la Cuenta Larga fueron establecidas con base a su relación con la fecha de final de tun 9.17.13.0.0 8 Ajaw 8 Wo):
9.17.13.0.8 8 Lamat 1 Pax (21 de noviembre, 783 d.C.)
9.17.13.1.8 2 Lamat 1 K'ayab' (11 de diciembre, 783 d.C.)
9.17.13.2.8 9 Lamat 1 Kumk'u (31 de diciembre, 783 d.C.)
9.17.13.3.13 8 B'en 1 Pop (25 de enero, 784 d.C.)
9.17.13.4.13 2 B'en 1 Wo (14 de febrero, 784 d.C.)
9.17.13.5.13 9 B'en 1 Sip (5 de marzo, 784 d.C.)
9.17.13.6.13 3 B'en 1 Sotz' (25 de marzo, 784 d.C.)
9.17.13.7.13 10 B'en 1 Tzek (14 de abril, 784 d.C.)
9.17.13.8.13 4 B'en 1 Xul (4 de mayo, 784 d.C.)

Como se desprende de la secuencia, estas fechas marcan el primer día de cada «mes» o winal después del inicio del catorceavo tun, lo que significa que están separadas por intervalos de veinte días. El día 3 Lamat 1 Wayeb', que forma parte del texto más temprano, no está incluido en la secuencia posterior. Debería de aparecer entre 9 Lamat 1 Kumk'u y 8 B'en 1 Pop:

\subsection{Lamat 1 Kumk'u (31 de diciembre, 783 d.C.) \\ 9.17.13.3.8 3 Lamat 1 Wayeb' (20 de enero, 784 d.C.) \\ 9.17.13.3.13 8 B'en 1 Pop ( 25 de enero, 784 d.C.)}

La colocación de la fecha Wayeb' en el texto principal sirve para acentuar su papel en los rituales que habrían tenido lugar junto con la dedicación del mural. Estos estuvieron supervisados por U Kit Kan Le'k, cuyas acciones fueron avaladas por su padre y su madre, quienes son mencionados en el texto (Lacadena 2004: 66). El emparejamiento de un final de tun y fechas rituales en el haab' no es una característica común de los textos del Clásico o Posclásico. Sin embargo, los rituales del asiento del tun se representan en el Códice de París, en el registro superior de las trece primeras páginas (Love 1994), mostrando una estructura similar a la de los rituales de asientos de haab' en el Códice de Madrid (por ejemplo, en las pp. 25d y 34-37). Sin embargo, en Ek' Balam no es el ritual de tun el que adquiere importancia, sino los finales de periodo en el calendario de haab' que están marcados, tal como están en el calendario de festivales que Landa describe en su Relación.

Debido al momento en que cae el final del tun, el primero de estos en la secuencia de Ek' Balam tiene lugar en el mes Pax (Lacadena 2004: 86). El festival de Pax es de interés porque se centró en temas relacionados con la guerra. Estructuralmente, puede estar relacionado con las ceremonias de Wayeb' en el sentido de que involucra

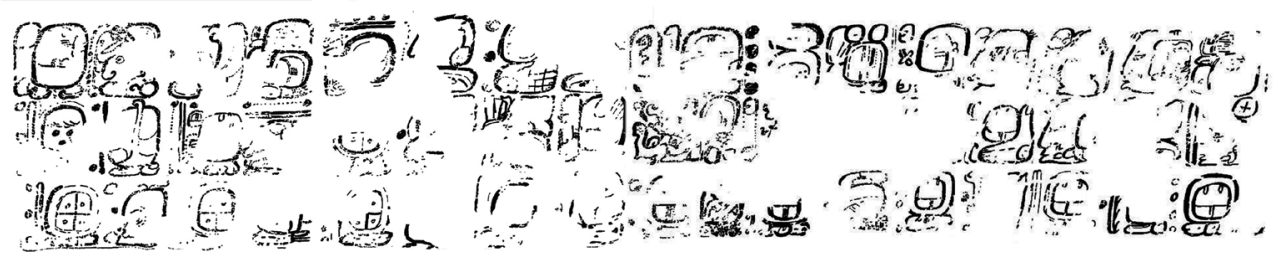

Figura 9. Ek' Balam: Mural de Cuarto 22 (Lacadena 2004: Fig. 22a-b). 
una procesión de una casa al templo, aunque en este caso es el general de guerra, el Nacón, quien fue acompañado «con gran pompa... de templo» (Landa 2000: 114). Además, como el Wayeb', el periodo ceremonial duró cinco noches. Al final de esto se celebró una gran fiesta, después de la cual se dio incienso a todos los señores y sacerdotes, para que los llevaran de vuelta a los pueblos donde residían, y el Nacón dio un discurso exhortándolos a celebrar las fiestas apropiadas en sus comunidades según lo dictado por el calendario ceremonial (Landa 2000: 114-115).

Al considerar el mural del Cuarto 22, uno podría verse tentado a imaginar al Nacón o el sacerdote, que proclama el nuevo tun, de pie frente al texto registrando las fechas que comienzan cada mes o winal y describiendo las ceremonias de importancia a cada uno. Los rituales de Wayeb' se centrarían nuevamente en el sur y en la deidad K'awiil, como fue el caso en el Mural A. Tal y como se sugirió previamente, U Kit Kan Le'k Tok' podría haber sentido una afinidad especial con los años Lamat debido a sus títulos que lo vinculan con K'awiil. K'awiil desempeñó un papel importante en las ceremonias dinásticas en las Tierras Bajas del sur y su importancia en el área norte puede ser sugerida no solo por su papel en las páginas k'atun del Códice de París, sino también por las muchas apariciones de K'awiil como la figura central en las tapas de bóveda. En estos contextos, parece encarnar los conceptos de sustento y abundancia, de manera similar a como lo hace en el Códice de Dresde. Puede ser por esta razón que K'awiil también aparece en muchas de las tapas de bóveda de U Kit Kan Le'k en Ek' Balam. Como el espíritu acompañante del gobernante, encarnaba el poder de la vida, sobre el maíz, las lluvias y sus súbditos.

\section{Consideraciones finales}

Otras tapas de bóveda muestran diferentes aspectos del gobernante, como el maíz mismo, una deidad con la capacidad de renacer; como el creador Itzamná, conocido por su sagacidad y habilidades de escribano; y como la Deidad Ave Principal, la encarnación de la gobernanza y un vínculo con el mundo de los espíritus. En cada uno de estos roles, U Kit Kan Le'k habría trabajado junto con el sumo sacerdote en el sitio, y habría servido como patrón de los escribas que registraron no solo sus obras, sino también las representaciones rituales que supervisó o ejecutó para mantener el mundo en equilibrio y su reino próspero.

Estos escribas siguen siendo figuras vagas, rara vez percibidas, pero con el poder de hacer que las declaraciones de las deidades se manifiesten con sus pinceles. Y se manifiesta una vez más con la recitación de la palabra escrita en una plegaria, petición o representación. Como apunta Allen Christenson (2003: 17-18) en relación al tiempo que pasó entre maya parlantes contemporáneos en las Tierras Altas de Guatemala, los textos se consideran sagrados y se les ofrece humo de incienso de copal antes de ser leídos. Según el guardián de los días que trabaja con Christenson esto se hizo porque: «leer los pensamientos de los ancestros [o deidades] antiguas es hacer que sus espíritus estén presentes en la habitación y darles una voz viva» (Don Vicente de León Abac; citado por Christenson 2003: 17-18). Aunque no podemos poner nombres o imágenes a los cientos de escribas que vivieron en Yucatán durante los períodos Clásico Tardío y Posclásico, las voces que capturaron de las deidades y reyes divinos viven gracias a ellos. 
Agradecimientos: Mi agradecimiento a Andrés Ciudad Ruiz y a Pepa Iglesias Ponce de León por reunir esta colección de artículos en memoria de nuestro querido amigo y colega y por la invitación a formar parte de ella, y a Armando Anaya por traducir mi texto. Alfonso nos llegó a todos de manera muy profunda.

\section{Referencias}

Barrera Vásquez, Alfredo, Juan Ramón Bastarrachea Manzano, William Brito Sansores, Refugio Vermont Salas, David Dzul Góngora y Domingo Dzul Poot, eds. 1995. Diccionario maya: maya-español, español-maya. $3^{\text {a }}$ edición. México: Editorial Porrúa.

Brasseur de Bourbourg, Charles E. 1869-70. Manuscrit Troano: Etudes sur le système graphique et la langue des Mayas. París: Imprimerie Impériale.

Bricker, Harvey M. y Victoria R. Bricker. 2011. Astronomy in the Maya Codices. Filadelfia: American Philosophical Society.

Bricker, Victoria R., Eleuterio Po'ot Yah y Ofelia Dzul de Po'ot. 1998. A Dictionary of the Maya Language as Spoken in Hocabá, Yucatán. Salt Lake City: University of Utah Press.

Christenson, Allen. 2001. Art and Society in a Highland Maya Community: The Altarpiece of Santiago Atitlan. Austin: University of Texas Press.

-2003. Popol Vuh: The Sacred Book of the Maya. Nueva York: O Books.

. 2016. The Burden of the Ancients: Maya Ceremonies of World Renewal from the Pre-Columbian Period to the Present. Austin: University of Texas Press.

Chuchiak, John F. IV. 2004. «The Images Speak: The Survival and Production of Hieroglyphic Codices and their Use in Post-Conquest Maya Religion (1580-1720)», en Continuity and Change: Maya Religious Practices in Temporal Perspective, Daniel Graña Behrens, Nikolai Grube, Christian Prager, Frauke Sachse, Stefanie Teufel y Elizabeth Wagner, eds., pp. 165-183. Acta Mesoamericana 14. Markt Schwaben: Anton Saurwein.

Clancy, Flora. 2009. The Monuments of Piedras Negras, an Ancient Maya City. Albuquerque: University of New Mexico Press.

Filloy Nadal, Laura. 2018. «The Importance of Visage, Facial Treatment, and Idiosyncratic Traits in Maya Royal Portraiture during the Reign of K'inich Janaab' Pakal of Palenque, 615-683 CE», en Social Skins of the Head: Body Beliefs and Ritual in Ancient Mesoamerica and the Andes, Vera Tiesler y María Cecilia Lozada, eds., pp. 109-127. Albuquerque: University of New Mexico Press.

Förstemann, Ernst. 1880. Die Maya Handschrift der Königlichen öffentlichen Bibliothek zu Dresden. Leipzig: Verlag der A. Naumannschen Lichtdruckeret.

Harrison-Buck, Eleanor, Astrid Runggaldier y Alec Gantos. 2018. «It's the Journey not the Destination: Maya New Year's Pilgrimage and Self-Sacrifice as Regenerative Power». Journal of Social Archaeology 18 (3): 325-347.

Houston, Stephen D. y Takeshi Inomata. 2009. The Classic Maya. Nueva York: Cambridge University Press.

Houston, Stephen D. y David Stuart. 2001. «Peopling the Classic Maya Court», en Royal Courts of the Classic Maya. Vol. 1: Theory, Comparison, and Synthesis, Takeshi Inomata y Stephen D. Houston, eds., pp. 54-83. Boulder: Westview Press.

Hull, Kerry y David Carrasco. 2004. «MAK-'Portal' Rituals Uncovered: An Approach to Interpreting Symbolic Architecture and the Creation of Sacred Space among the Maya», en Continuity and Change: Maya Religious Practices in Temporal Perspective, Daniel Graña Behrens, Nikolai Grube, Christian Prager, Frauke Sachse, Stefanie Teufel y Eli- 
zabeth Wagner, eds., pp. 134-140. Acta Mesoamericana 14. Markt Schwaben: Saurwein Verlag.

Inomata, Takeshi. 2011. «The Power and Ideology of Artistic Creation: Elite Craft Specialists in Classic Maya Society». Current Anthropology 42 (3): 321-349.

Knowlton, Timothy. 2010. Maya Creation Myths: Words and Worlds of the Chilam Balam. Boulder: University Press of Colorado.

Knowlton, Timothy y Gabrielle Vail. 2010. «Hybrid Cosmologies in Mesoamerica: A Reevaluation of the yax cheel cab, a Maya World Tree». Ethnohistory 57 (4): 709-739.

Lacadena, Alfonso. 2000. «Los escribas del Códice de Madrid: Metodología paleográfica». Revista Española de Antropología Americana 30: 27-85.

. 2004. The Glyphic Corpus from Ek'Balam, Yucatán. FAMSI Grantee Reports. http: //www.famsi.org/reports/01057/index.html

- 2010. «Highland Mexican and Maya Intellectual Exchange in the Late Postclassic: Some Thoughts on the Origin of Shared Elements and Methods of Interaction», en $\mathrm{As}$ tronomers, Scribes, and Priests: Intellectual Interchange between the Northern Maya Lowlands and Highland Mexico during the Late Postclassic Period, Gabrielle Vail y Christine Hernández, eds., pp. 383-405. Washington, D.C.: Dumbarton Oaks.

Landa, Fray Diego de. 2000 [c.1566]. Relación de las cosas de Yucatán: Escrita por el Obispo de Yucatán, basado en las tradiciones orales de los antiguos Mayas. México: Monclem Ediciones.

Las Casas, Fray Bartolomé de. 1967 [c.1550]. Apologética historia sumaria de las Indias. 2 vols. México: Instituto de Investigaciones Históricas, Universidad Nacional Autónoma de México.

Love, Bruce. 1994. The Paris Codex: Handbook for a Maya Priest. Austin: University of Texas Press.

Martínez Hernández, Juan, ed. 1929. Diccionario de Motul maya-español atribuido a fray Antonio de Ciudad Real, y Arte de la lengua maya por fray Juan Coronel. Mérida: Talleres de la Compañía Tipográfica Yucateca.

Mathews, Peter. 1993. The Proceedings of the Maya Hieroglyphic Weekend, October 31November 1, 1992. Transcripción de Phil Wanyerka. Cleveland: Cleveland State University.

Proskouriakoff, Tatiana. 1962. «The Artifacts of Mayapan», en Mayapan, Yucatan, Mexico, Harry E.D. Pollock, Ralph L. Roys, Tatiana Proskouriakoff y A. Ledyard Smith, eds., pp. 321-442. Washington, D.C.: Carnegie Institution of Washington.

Pugh, Timothy, Prudence M. Rice, Evelyn Chan Nieto y Don S. Rice. 2016. «A Chak'an Itza Center at Nixtun-Ch'ich', Petén, Guatemala». Journal of Field Archaeology 41 (1): 1-16.

Reents-Budet, Dorie. 1994. Painting the Maya Universe: Royal Ceramics of the Classic Period. Durham: Duke University Press.

Rosny, Léon de. 1883. Codex Cortesianus. Manuscrit hiératique des anciens indiens de l'Amérique Centrale, conservé au Musée Archéologique de Madrid. París: Libraires de la Société d'Ethnographie.

Rossi, Franco, William A. Saturno y Heather Hurst. 2015. «Maya Codex Book Production and the Politics of Expertise: Archaeology of a Classic Period Household at Xultun, Guatemala». American Anthropologist 117 (1): 116-132.

Saturno, William A., Franco Rossi, David Stuart y Heather Hurst. 2017. «A Maya curia regis: Evidence for a Hierarchical Specialist Order at Xultun, Guatemala». Ancient Mesoamerica 28 (2): 423-440.

Seler, Eduard. 1902-23. Gesammelte Abhandlungen zur Amerikanischen Sprach-und Alterthumskunde. 5 vols. Berlin: A. Asher. 
Stuart, David y George Stuart. 2008. Palenque: Eternal City of the Maya. Nueva York: Thames and Hudson.

Taube, Karl A. 1988a. The Ancient Yucatec New Year Festival: The Liminal Period in Maya Ritual and Cosmology. Tesis Doctoral. New Haven: Yale University.

- 1988b. «A Prehispanic Maya Katun Wheel». Journal of Anthropological Research 44 (2): 183-203.

1992. The Major Gods of Ancient Yucatan. Studies in Pre-Columbian Art and Archaeology 32. Washington, D.C.: Dumbarton Oaks.

-1993. Aztec and Maya Myths. Austin y Londres: University of Texas y The British Museum.

Taube, Karl A., William A. Saturno, David Stuart y Heather Hurst. 2010. «The Murals of San Bartolo, El Petén, Guatemala; Part 2: The West Wall». Ancient America 10. Barnardsville: Boundary End Archaeology Research Center.

Thompson, J. Eric S. 1934. «Sky Bearers, Colors, and Directions in Maya and Mexican Religion», en Contributions to American Archaeology 10, pp. 209-242. Washington, D.C.: Carnegie Institution of Washington.

Vail, Gabrielle. 2005. «Renewal Ceremonies in the Madrid Codex», en Painted Books and Indigenous Knowledge in Mesoamerica: Manuscript Studies in Honor of Mary Elizabeth Smith, Elizabeth Hill Boone, ed., pp. 179-209. Middle American Research Institute 69. Nueva Orleans: Tulane University.

- 2015. «Scribal Interaction and the Transmission of Traditional Knowledge: A Postclassic Maya Perspective». Ethnohistory 62 (3): 445-468.

Vail, Gabrielle y Christine Hernández. 2002-2018. Maya Hieroglyphic Codices Database. http://mayacodices.org.

-2013. Re-creating Primordial Time: Foundation Rituals and Mythology in the Postclassic Maya Codices. Boulder: University Press of Colorado.

Vail, Gabrielle y Matthew G. Looper. 2015. «World Renewal Rituals among the Postclassic Yucatec Maya and Contemporary Ch'orti' Maya». Estudios de Cultura Maya 45: 121 140.

Vail, Gabrielle y Andrea Stone. 2002. «Representations of Women in Postclassic and Colonial Maya Literature and Art», en Ancient Maya Women, Traci Ardren, ed., pp. 203-228. Walnut Creek: Alta Mira Press.

Villacorta, J. Antonio y Carlos A. Villacorta. 1976 [1930]. Códices mayas. Guatemala: Tipografía Nacional.

Ximénez, Francisco. 1929-31 [1722]. Historia de la provincia de San Vicente de Chiapa y Guatemala. Biblioteca «Goathemala» de la Sociedad de Geografía e Historia de Guatemala, Tomos I, II y III. Guatemala: Tipografía Nacional. 